Article

\title{
The Study on the Overall Plasma Electrolytic Oxidation for 6061-7075 Dissimilar Aluminum Alloy Welded Parts Based on the Dielectric Breakdown Theory
}

\author{
Yanfei Chen ${ }^{1}$ (D), Xiaocun Song ${ }^{1, *}$, Jixue Zhou ${ }^{1,2}$, Hongtao Liu ${ }^{1,3}$ and Yuansheng Yang 4 \\ 1 Advanced Materials Institute, Shandong Academy of Sciences, Jinan 250014, China; \\ sunshineyanfei@126.com (Y.C.); zhoujx@sdas.org (J.Z.); hongtaoliu@sdas.org (H.L.) \\ 2 Shandong Engineering Research Center for Lightweight Automobiles Magnesium Alloys, \\ Jinan 250014, China \\ 3 Shandong Key Laboratory for High Strength Lightweight Metallic Materials (HLM), Jinan 250014, China \\ 4 Institute of Metal Research Chinese Academy of Sciences, Shenyang 110016, China; ysyang@imr.ac.cn \\ * Correspondence: sunshinesxc@126.com
}

Received: 29 November 2017; Accepted: 29 December 2017; Published: 2 January 2018

\begin{abstract}
Electrical connection of dissimilar metals will lead to galvanic corrosion. Therefore, overall surface treatment is necessary for the protection of dissimilar metal welded parts. However, serious unbalanced reactions may occur during overall surface treatment, which makes it difficult to prepare integral coating. In this paper, an overall ceramic coating was fabricated by plasma electrolytic oxidation to wrap the 6061-7075 welded part integrally. Moreover, the growth mechanism of the coating on different areas of the welded part was studied based on the dielectric breakdown theory. The reaction sequence of each area during the treatment was verified through specially designed dielectric breakdown tests. The results showed that the high impedance overall of ceramic coating can inhibit the galvanic corrosion of the 6061-7075 welded part effectively.
\end{abstract}

Keywords: overall plasma oxidation; dielectric breakdown; ceramic coating; dissimilar metal welded parts; welded joint

\section{Introduction}

The mix and match use of strong/weak materials can be applied to prepare functionally graded materials (FGM), and it is also an effective way to achieve lightweight structure [1,2]. However, magnesium alloys connected with aluminum or other lightweight alloys would suffer from serious galvanic corrosion, which limits the application of FGM in aviation and marine engineering [3]. The overall surface protection of dissimilar metal connecting parts can curb the generation and extension of corrosion effectively [4]. Therefore, it is necessary to conduct in-depth research on the surface anti-corrosion technology for collaborative usage of lightweight structural materials. Plasma electrolytic oxidation is one of the most effective corrosion protection techniques for magnesium and aluminum alloys [5]. It can not only improve the decorative properties of the workpiece but can also prepare high impedance or insulated ceramic coating with low cost and low energy consumption [6,7].

However, the physical properties, and chemical and electrochemical activity differences between the materials make it difficult to conduct overall surface treatment for dissimilar metal connected parts. Serious unbalanced reactions would occur during the process, which would reduce the overall corrosion resisting performance significantly [8].

In this paper, 6061 and 7075 aluminum alloys were friction stir welded, and overall plasma oxidation treatment was applied to surface protect the welded parts. Friction stir welding (FSW) 
is an important solid-phase joining method for the preparation of FGM, especially for light alloys such as magnesium, aluminum, copper, titanium and their alloys. It can prevent the occurrence of embrittlement and weakening phase in welding joints [9]. However, FSW changed the property of welding area, therefore the morphology and composition of the coating on the surface of the welding area and base metals (6061/7075) were different. Based on the dielectric breakdown theory, the growth mechanism of ceramic coating on different areas of 6061-7075 welded part was explored and explained. Based on the experimental results obtained, a possible mechanism for the formation of overall ceramic coating was proposed. Furthermore, the results showed that the corrosion resistance of the 6061-7075 welded part was improved and the potential corrosion difference between base metals and welding area was reduced significantly by overall plasma oxidation.

\section{Experimental}

\subsection{Materials}

The substrate materials used in this investigation were 6061 and 7075 aluminum alloys with the chemical compositions shown in Tables 1 and 2. The 6061 and 7075 aluminum alloys were cut into cubical sheets with a dimension of $50 \times 150 \times 4 \mathrm{~mm}^{3}$. Then, the 6061 aluminum and 7075 aluminum sheets were butt friction stir welded before overall plasma electrolytic oxidation. All solvents and chemicals used were of a chemically pure grade without any further purification.

Table 1. Chemical composition of 6061 aluminum alloy.

\begin{tabular}{cccccccc}
\hline $\mathbf{S i}$ & $\mathbf{F e}$ & $\mathbf{C u}$ & $\mathbf{M n}$ & $\mathbf{M g}$ & $\mathbf{C r}$ & $\mathbf{Z n}$ & $\mathbf{A l}$ \\
\hline 0.59 & 0.42 & 0.19 & 0.01 & 0.93 & 0.18 & 0.12 & balance \\
\hline
\end{tabular}

Table 2. Chemical composition of 7075 aluminum alloy.

\begin{tabular}{cccccccc}
\hline Si & Fe & Cu & Mn & Mg & Cr & Zn & Al \\
\hline 0.05 & 0.16 & 1.43 & 0.02 & 2.58 & 0.23 & 5.79 & balance \\
\hline
\end{tabular}

\subsection{Pre-Treatment}

Butt surface and surface of 6061 and 7075 aluminum sheets were polished mechanically using progressively finer grades of emery papers and then ultrasonically degreased in acetone before friction stir welding. An X5032 type friction stir welding machine equipped with a right-hand thread stirring head was used to weld the polished dissimilar aluminum sheets [10]. The length and diameter of the stir pin were 3.6 and $4 \mathrm{~mm}$, respectively, and the diameter of the shoulder was $16 \mathrm{~mm}$. The stirring head was tilted $2^{\circ}$ in the feeding direction. Stirring speed was set at $950 \mathrm{r} / \mathrm{min}$, and the rotating shoulder was pressed into the substrate metals for $0.2 \mathrm{~mm}$ and stayed for $5 \mathrm{~s}$ to preheat the base metals. The feeding rate was set at $37.5 \mathrm{~mm} / \mathrm{min}$.

The beginning and end of the weld joints were cut from the welded 6061-7075 parts by wire-electrode cutting. Then, all these samples were metallographically grounded using 600-1200 grit silicon carbide papers, rinsed with deionized water, ultrasonically degreased in acetone for $20 \mathrm{~min}$, and finally dried in cold air before overall plasma electrolytic oxidation.

\subsection{Overall Plasma Electrolytic Oxidation}

The overall ceramic coatings on the surface of 6061-7075 welded parts were prepared with a JHMAO-DY-200 type $200 \mathrm{~kW}$ DC pulse plasma electrolytic oxidation system, which was manufactured at Xi'an University of Technology. The 6061-7075 welded part was used as anode, and a stainless steel sheet was used as the cathode. 
The electrolyte was prepared by dissolving $6 \mathrm{~g} / \mathrm{L} \mathrm{Na}_{2} \mathrm{SiO}_{3}, 8 \mathrm{~g} / \mathrm{L} \mathrm{KOH}, 8 \mathrm{~g} / \mathrm{L} \mathrm{KF}, 0.5 \mathrm{~g} / \mathrm{L} \mathrm{Na}_{2} \mathrm{WO}_{4}$ and $6 \mathrm{~g} / \mathrm{L}\left(\mathrm{NaPO}_{3}\right)_{6}$ in deionized water. The electrolyte temperature was controlled automatically at $30 \pm 5{ }^{\circ} \mathrm{C}$. The $\mathrm{pH}$ value before plasma electrolytic oxidation was in the range of $11-12$. The whole process $(10 \mathrm{~min})$ was carried out under a constant current density of $30 \mathrm{~mA} / \mathrm{cm}^{2}$ at $500 \mathrm{~Hz}$ with a duty cycle of $10 \%$ and the maximum voltage applied was $400 \mathrm{~V}$. The treated samples were rinsed with alcohol in ultrasonic bath for $10 \mathrm{~min}$ and dried in cold air [11,12].

\subsection{Characterization and Testing}

The thickness of the coating was measured by a Time TT230 type coating thickness gauge (TIME Group INC, BeiJing, China). The surface and cross-sectional morphology of the coatings were investigated by ZEISS EVO MA 10/LS 10 type scanning electron microscope (SEM) (ZEISS Group, Jena, Germany), and their elemental composition was determined by OXFORD X-Max type energy dispersive spectrometer (EDS) (Oxford Instruments, Oxford, UK). To determine the phase composition, a Bruker D2 PHASER X-ray diffraction (XRD) (Bruker Corporation., Karlsruhe, Germany) with Cu K $\alpha$ radiation was used. The current and voltage of the dielectric breakdown were detected by a Nanjing Changjiang CJ2671S type hipot tester.

All electrochemical experiments were carried out in a $3.5 \mathrm{wt} \% \mathrm{NaCl}$ aqueous solution at room temperature using a Shanghai Chenhua CHI660E electrochemical system. The electrochemical cell consisted of a three-electrode system. The tested sample was used as the working electrode. The platinum sheet was used as the counter electrode, and the saturated calomel electrode $\left(\mathrm{Hg} / \mathrm{Hg}_{2} \mathrm{Cl}_{2}\right.$ in saturated solution of $\mathrm{KCl}$ ) was used as the reference electrode [13]. Specimens for electrochemical test were sampled from the center interface of 6061,7075 and welding area of the treated dissimilar aluminum connecting parts. The working electrode was set in a custom-made Teflon holder, which had a circular $1 \mathrm{~cm}$ window exposed to the electrolyte solution. The exposed circular area was $0.785 \mathrm{~cm}^{2}$, as shown in Figure 1. Besides, the scanning speed of the potentiodynamic electrochemical tests was $3 \mathrm{mV} / \mathrm{s}$. The Tafel curves were obtained after the electrodes were placed in the $\mathrm{NaCl}$ solution for $60 \mathrm{~s}$, so the electrolytes were fully infiltrated by the solution, and the obtained curves were used to deduce the equilibrium potential $E_{\text {corr }}$ and $i_{\text {corr }}$. The corrosion resistance of the ceramic layer can be compared by the measured corrosion current intensity $i_{\text {corr }}[14]$.
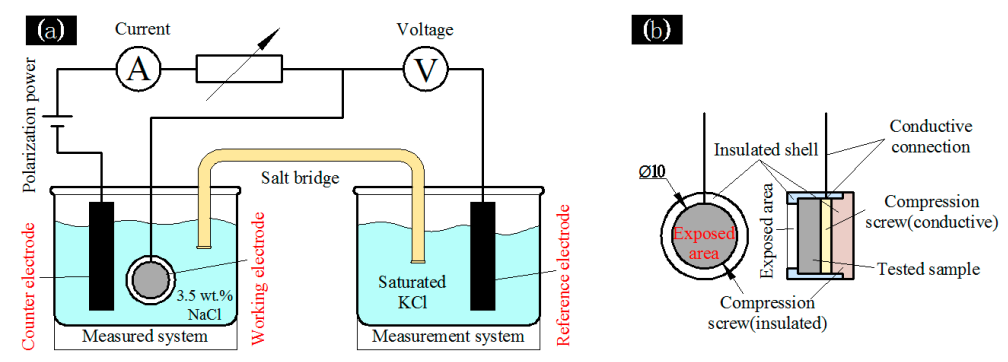

Figure 1. The sealed and insulated fixture for electrochemical test. (a) The schematic of three-electrode system; (b) the schematic of working electrode [15].

\section{Results and Discussion}

The 6061 and 7075 dissimilar aluminum alloys were successfully friction stir welded, as shown in Figure 2a,b. Overall, plasma electrolytic oxidation was applied to surface the to protect the welded parts, and the welded parts were integrally wrapped by a ceramic coating with 10 min overall plasma electrolytic oxidation treatment, as shown in Figure 2c,d. In other words, the ceramic coating grew on all areas contacted with the electrolyte, including 7075, 6061 and the welding joints surface. Thereby, an integral and sealed protective layer formed. As a result, the insulated ceramic coating isolates the 6061-7075 welded part from corrosion media, and broke the electronic circuit of corrosion to improve 
the corrosion resistance of welded part [16]. The schematic diagram of overall ceramic coating on the surface of 6061-7075 welded parts is presented in Figure 3.

There was a slight color difference between the ceramic coating on base metals $(6061 / 7075$, white) and welding area (slight yellow) because the surface elements distribution of welding area was changed by friction stir process. The color of the coating on 6061 and 7075 was almost the same, since the main alloying elements were similar.
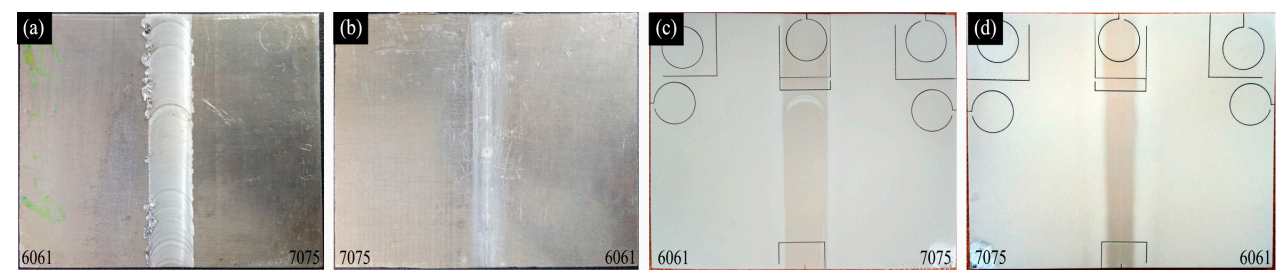

Figure 2. The 6061-7075 welded part: (a) top surface; (b) bottom surface; (c) top surface of treated specimen; and (d) bottom surface of treated specimen.

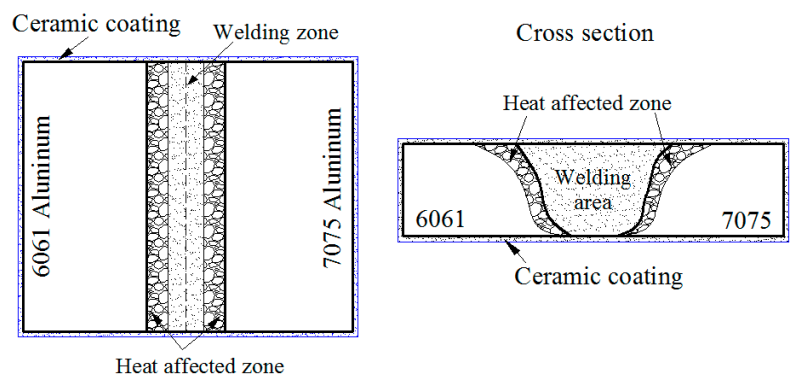

Figure 3. Schematic diagrams of the overall ceramic coating.

Figure 4 shows the microstructure in different areas of the friction stir welded part. The grain size of the initial base metals was about $40 \mu \mathrm{m}$, as shown in Figure 4a; as a similar situation occurred for 6061 aluminum alloy, it is not shown here. The cross section microstructure and the surface microstructure of the welding joint shown in Figure $4 b, c$ revealed significant differences between the welding area and the base metals (heat affected zone). The grain in welding area was broken into extremely small size (about $2 \mu \mathrm{m}$ ) by the stirring pin, as shown in Figure $4 \mathrm{~d}$, and the grains in thermo-mechanical affected zone were elongated and deformed. It is obvious that the surface of the welded part was divided into different areas based on the grain type.
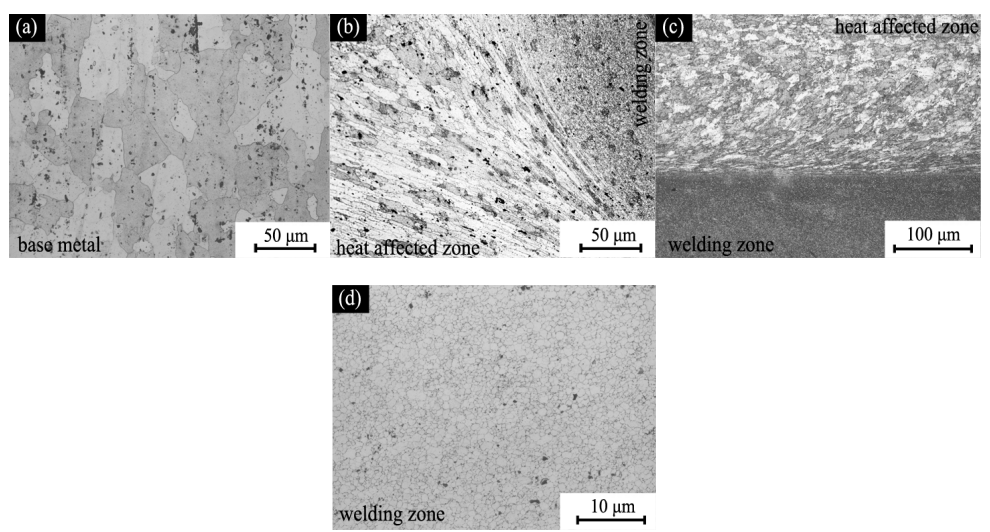

Figure 4. Optical micrographs of welded part: (a) 7075; (b) cross section of the welding zone; (c) top surface of the welding zone; and (d) welding zone. 


\subsection{SEM Morphology and EDS Analysis of the Ceramic Coating}

Figure 5 shows the morphology of ceramic coating on the surface of 6061,7075 and welding area. Considerable amounts of micropores were randomly distributed on the surface of the coatings [17]. Therefore, the morphology of the coating was relatively rough. Micropores formed when the molten oxides and gas bubbles ejected from discharge channels [18,19]. Obviously, the morphology of the ceramic coating on the surface of welding area was different from the coatings on base metals (6061, 7075), as shown in Figure 5a-c. Many island-shaped and volcano-like objects grew on the surface of welding area. Conversely, the coating on 6061 and 7075 surfaces was much more consistent and flat. The observation from high magnification in Figure 5d-f showed that the coatings on 6061 and 7075 had a similar porous structure, and the diameter of the pores was about $0.5-2 \mu \mathrm{m}$. However, the island-shaped and porous objects on the coating of welding area seemed to grow on a dense basal layer, and it had a similar porous structure as the coating on 6061/7075, which can be seen in Figure 5d-f. In other words, the ceramic coating on welding area consisted of a porous layer and a dense basal layer from the top to the bottom.

Besides, the number of randomly distributed island-shaped porous layers gradually decreased along the 6061/7075 aluminum area to welding area, as shown in Figure 6. To further explore the growth mechanism differences between the ceramic coating on base metals and welding area, EDS linear scan was used to analyze the island-shaped porous layer and the dense basal layer. The results in Figure 7 showed that the intensity of silicon (Si) element rose in the island-shaped porous layer, whereas the intensity of aluminum (Al) decreased.
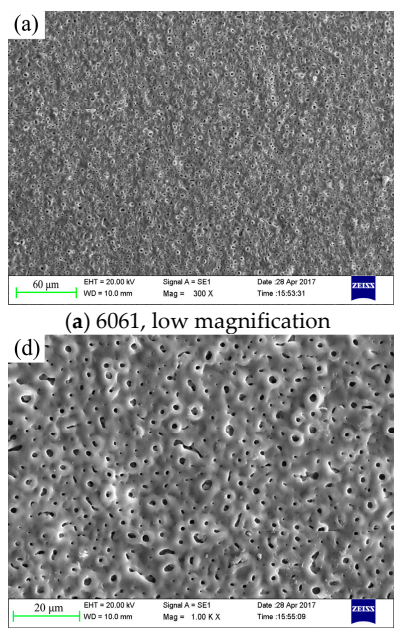

(d) 6061, high magnification
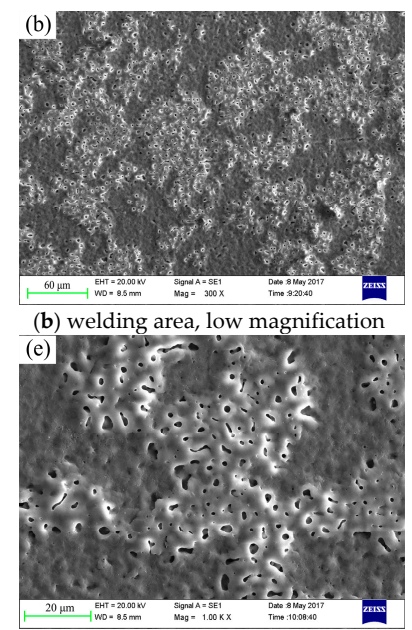

(e) welding area, high magnification

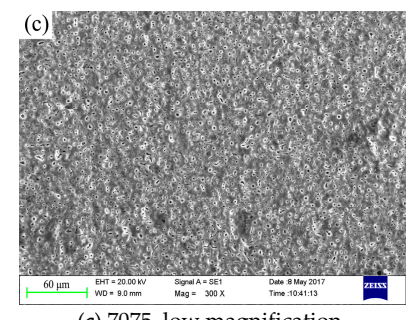

(c) 7075 , low magnification

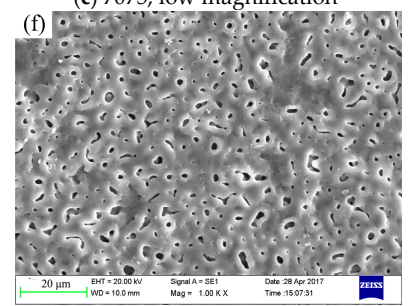

(f) 7075 , lohigh magnification

Figure 5. SEM morphology of the ceramic coating on: (a,d) 6061; (b,e) welding area; and (c,f) 7075.

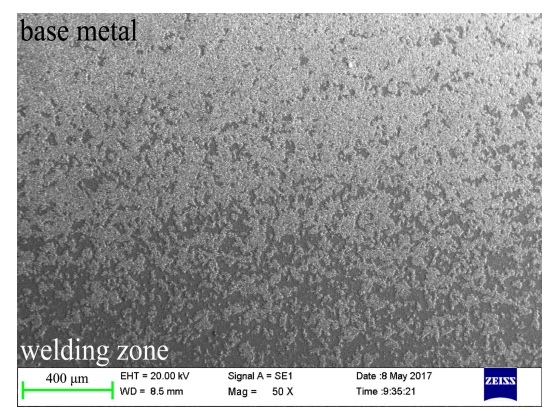

Figure 6. Morphology of the island-shaped porous layer. 


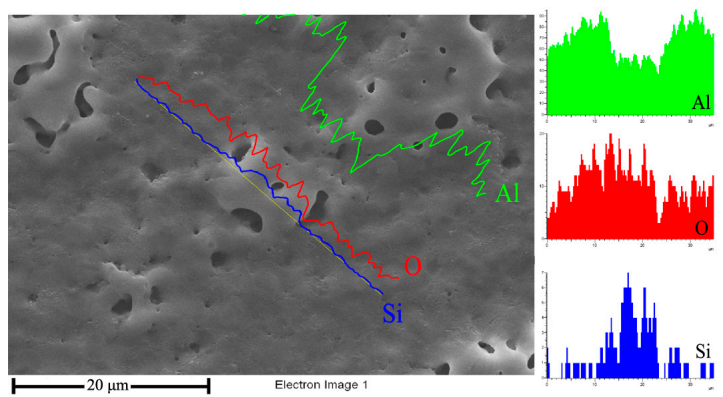

Figure 7. EDS linear scan of the island-shaped porous layer.

Moreover, EDS analysis in Figure 8a-d indicated that the porous ceramic coating on 6061/7075 and the porous island-shaped layer on welding area had a similar elemental composition; the intensity of elemental composition was similar too. They consisted of $\mathrm{Al}, \mathrm{O}, \mathrm{Si}$, and P. However, the dense basal layer on the welding area was made up of $\mathrm{O}$ and $\mathrm{Al}$, as shown in Figure 8d, and the main composition was inferred as $\mathrm{Al}_{2} \mathrm{O}_{3}$. The difference reflected that a time sequence or growth priority existed during the growth process of the overall ceramic coating: the dense basal layer formed first on the surface of base metal, and the porous layer then grew on the dense basal layer $[15,20,21]$.

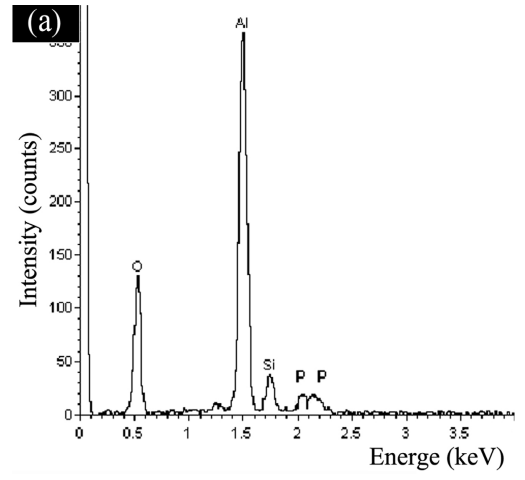

(a) 6061

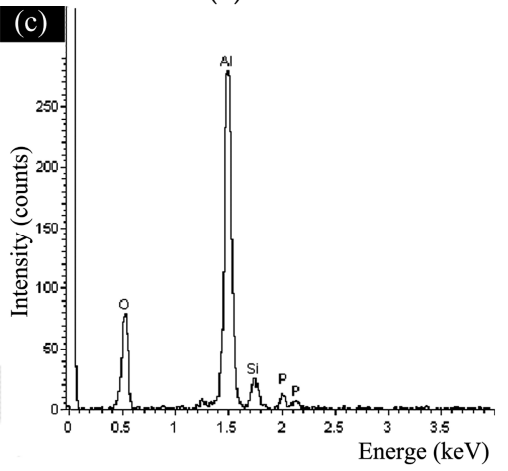

(c) Island-shaped porous layer on welding area

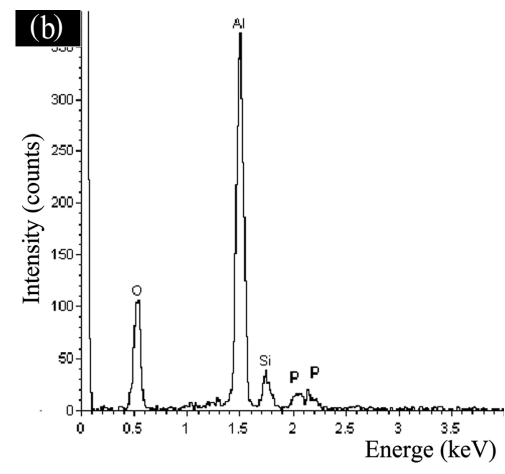

(b) 7075

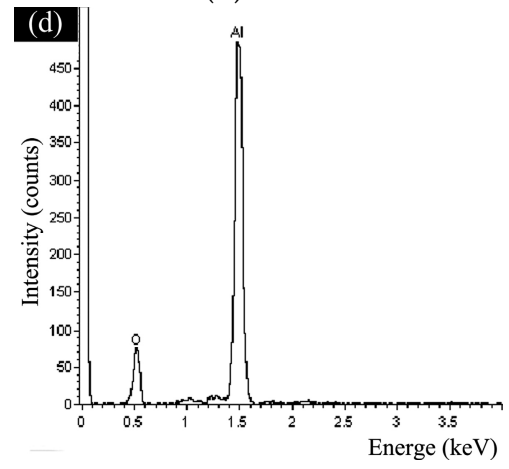

(d) Dense basal layer on welding area

Figure 8. The EDS results of the coating on each areas: (a) 6061; (b) 7075; (c) island-shaped porous layer; and (d) dense basal layer.

\subsection{Cross-Section Morphologies and Analysis of the Ceramic Coating}

Cross-sectional morphology and EDS analysis of the ceramic coatings on the surface of 6061, 7075 and welding area are shown in Figure 9. The thickness of the coating on 6061, 7075 and welding area was about 5, 4 and $3.5 \mu \mathrm{m}$ on average, respectively. Clearly, the coating on 6061,7075 and welding area was integrated firmly with the metal substrate by sintered interlocking. In addition, the difference 
in thickness proved that the reaction priority or sequence of different areas in 6061-7075 welded part existed during overall plasma oxidation.

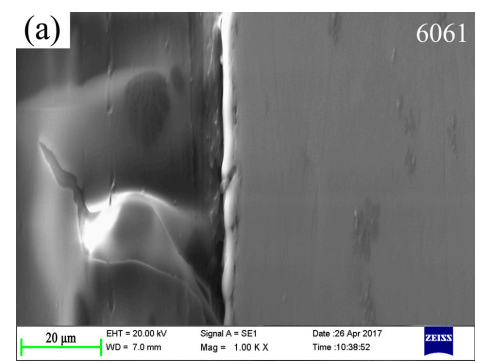

(a) 6061, low magnification

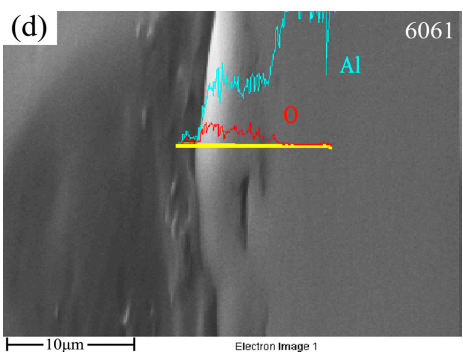

(d) 6061, high magnification

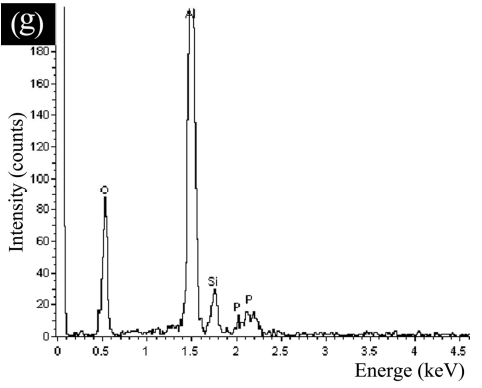

(x) 6061, EDS

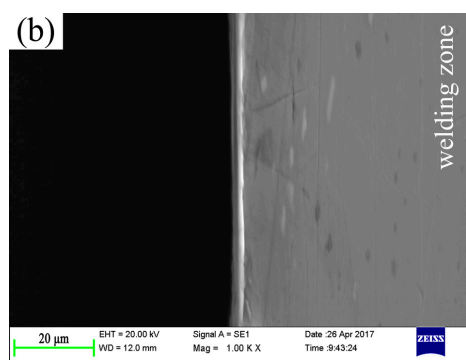

(b) welding area, low magnification

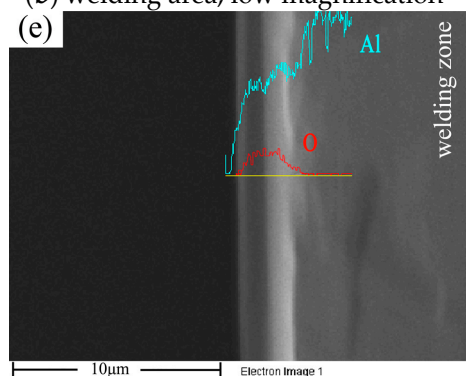

(e) welding area, high magnification
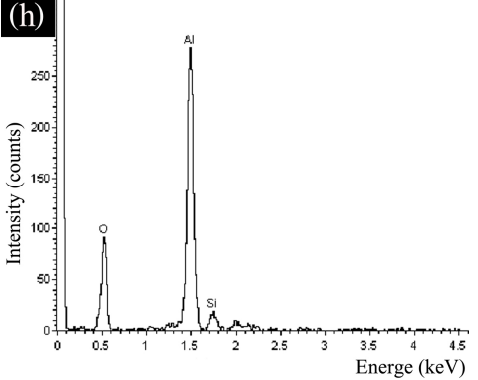

(y) welding area, EDS

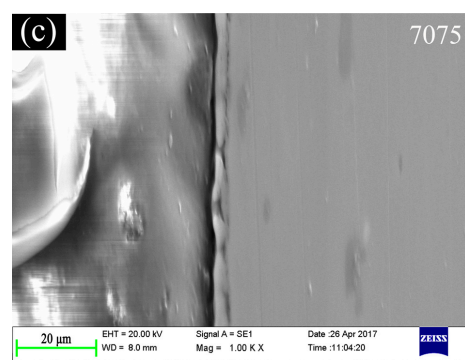

(c) 7075 , low magnification

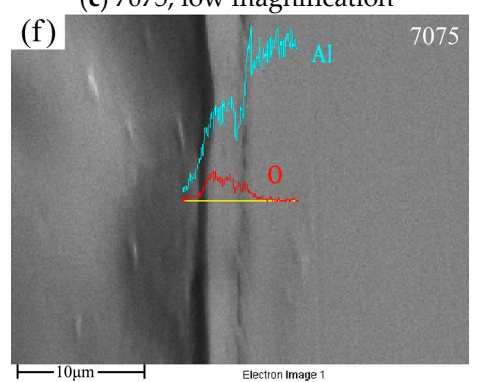

(f) 7075 , lohigh magnification

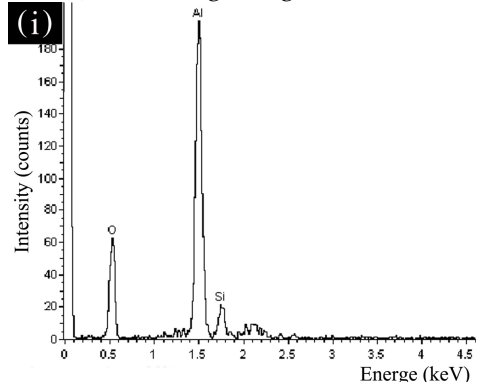

(z) 7075, EDS

Figure 9. The cross-section morphology and EDS analysis of the ceramic coating on: 6061 (a,d,g); welding area $(\mathbf{b}, \mathbf{e}, \mathbf{h})$; and $7075(\mathbf{c}, \mathbf{f}, \mathbf{i})$.

Besides, the surface morphology in Figure 5 showed that countless micropores distributed on the surface of ceramic coating, while pores were not found in the cross-section morphology in Figure 9d-f, except for a dense layer. This was important evidence that the dense layer occupied a high proportion (close to $100 \%$ ) of the entire ceramic coating. In fact, the pores would permit more corrosive inter medium to be absorbed into the ceramic coating and decrease the corrosion resistance. In conventional plasma oxidation treatment [22,23], this dense layer was the main protective layer of the ceramic coating, which only accounting for about $60 \%$ of the total thickness. Therefore, the current overall plasma oxidation treated 6061-7075 welded parts exhibited excellent integral corrosion resistance, as discussed in Section 3.5.

EDS analysis of the cross section is shown in Figure $9 \mathrm{~g}-\mathrm{i}$. It was obvious that main constituent elements of the ceramic coating in different area of the 6061-7075 welded part were almost the same. The main elements were $\mathrm{Al}, \mathrm{O}, \mathrm{Si}$ and $\mathrm{P}$, and the intensity of the elements in each area was slightly different.

\subsection{XRD Analysis of the Ceramic Coating in Each Area of the 6061-7075 Welded Part}

X-ray diffraction (XRD) was applied to accurately detect the components of the ceramic coating in different areas of 6061-7075 welded part, and the results are shown in Figure 10. 


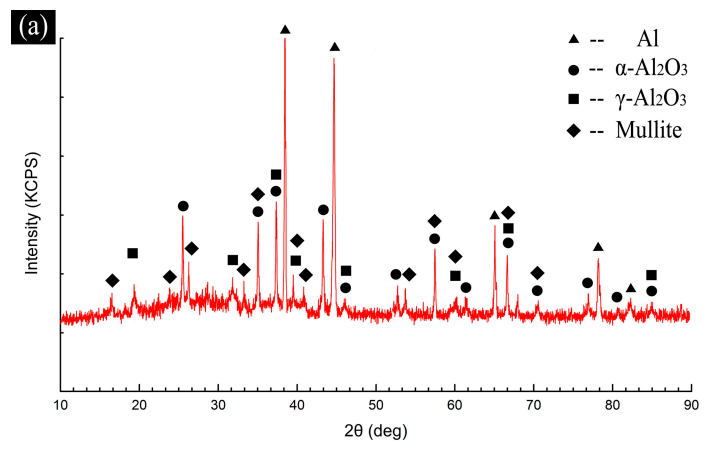

(a) XRD results of the coating on 6061

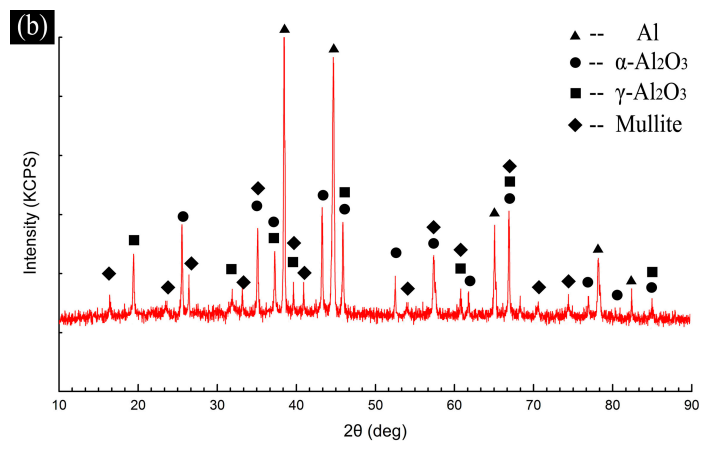

(b) XRD results of the coating on 7075 - - $\mathrm{Al}$ -- $\alpha-\mathrm{Al}_{2} \mathrm{O}_{3}$ - - $\gamma-\mathrm{Al}_{2} \mathrm{O}_{3}$

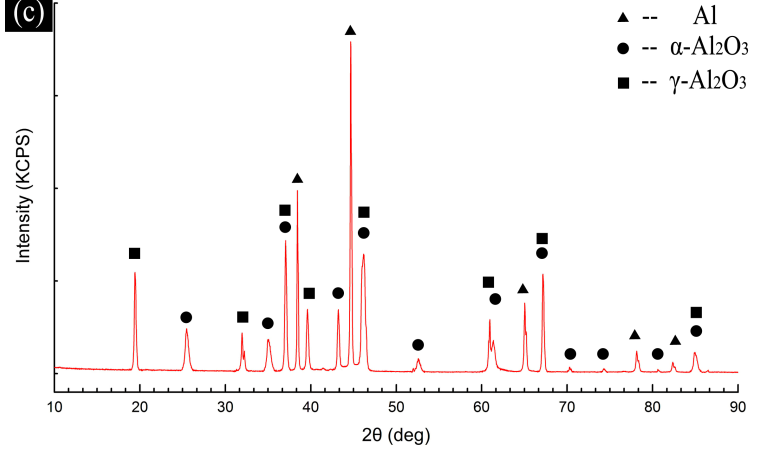

(c) XRD results of the coating on the middle of welding area

Figure 10. XRD results of the coating: (a) 6061; (b) 7075; and (c) middle of welding area.

By comparing the XRD results, the components of the porous coating on the surface of 6061 and 7075 were almost the same, i.e., $\alpha-\mathrm{Al}_{2} \mathrm{O}_{3}, \gamma-\mathrm{Al}_{2} \mathrm{O}_{3}$ and small amount of mullite $\left(3 \mathrm{Al}_{2} \mathrm{O}_{3}-2 \mathrm{SiO}_{2}\right)$. However, the main components of the coating on weld zone (middle position) were $\alpha-\mathrm{Al}_{2} \mathrm{O}_{3}$ and $\gamma-\mathrm{Al}_{2} \mathrm{O}_{3}$ since the middle position of welding area was mainly covered by dense basal layer and small amount of distributed island-shaped porous layer, as shown in Figure $5 \mathrm{~b}$,e, thus the diffraction peak data obtained were mainly those of the dense basal layer. The XRD results were identical to the EDS analysis results in Figure 8 [24].

However, peak intensity of the $\gamma-\mathrm{Al}_{2} \mathrm{O}_{3}$ decreased from welding area to 7075 and to 6061 , while the peak intensity of $\alpha-\mathrm{Al}_{2} \mathrm{O}_{3}$ showed an opposite tendency. This trend was related to the conversion of $\gamma-\mathrm{Al}_{2} \mathrm{O}_{3}$ to $\alpha-\mathrm{Al}_{2} \mathrm{O}_{3}$ during plasma oxidation process, on the one hand, and the reaction priority and sequence of the different areas in 6061-7075 welded part, on the other hand. The $\gamma-\mathrm{Al}_{2} \mathrm{O}_{3}$ would convert into $\alpha-\mathrm{Al}_{2} \mathrm{O}_{3}$ irreversibly at $1050-1500{ }^{\circ} \mathrm{C}$ and the micro arc generated during plasma oxidation process provided the temperature conditions for the conversion [25].

Besides, there were obvious diffuse scattering peaks in the XRD results of the unpolished porous ceramic coating, as shown in Figure 10a,b, while similar diffuse scattering peaks did not appear in the XRD results of dense basal layer, as shown in Figure 10c. There was some amount of P-containing amorphous or amorphous $\mathrm{SiO}_{2}$ in the porous ceramic coating, considering that $\mathrm{P}$ was detected in the porous coating by EDS analysis, while crystalline material of $\mathrm{P}$ was not found in XRD results [26,27]. According to the growth mechanism proposed in this paper, small amount of $\mathrm{SiO}_{3}{ }^{2-}$ and $\mathrm{PO}_{4}{ }^{3-}$ in electrolyte participated in the reaction and formed high temperature melt. The outer layer formed at high temperature melts and sharply cooled under the chilling effect of the electrolyte, during which a certain amount of Si or P-containing amorphous phase formed in the outer shell of the melt. Then, they randomly distributed in the ceramic coating.

In addition, with the temperature conditions produced by the micro arc at about $1470{ }^{\circ} \mathrm{C}$, solid-state thermal reaction occurred between the $\mathrm{Al}_{2} \mathrm{O}_{3}$ and randomly distributed $\mathrm{SiO}_{2}$ which resulted in the formation of mullite at the interface of $\mathrm{Al}_{2} \mathrm{O}_{3}$ and $\mathrm{SiO}_{2}$ [28], which was part of the growth mechanism of the ceramic coating. 


\subsection{The Growth Mechanism of the Overall Ceramic Coating Based on the Dielectric Breakdown Theory}

According to the classic plasma oxidation mechanism [29], the aluminum was rapidly oxidized and ejected from the discharge channels with the generation of discharge sparks. Meanwhile, small amount of $\mathrm{SiO}_{3}{ }^{2-}$ and $\mathrm{PO}_{4}{ }^{3-}$ in the electrolyte diffused into the discharge channels to participate in the reaction forming high temperature melt. The high temperature melt then cooled down and formed the dense basal layer. Thus, it was clear that the dense layer, which formed first, was mainly made of aluminum oxide and a small amount of Si and P containing substances, which was verified through EDS and XRD in the previous sections. As the plasma oxidation proceeded, the ceramic coating was much more difficult to breakdown, since it was thickening constantly. As a result, the number of

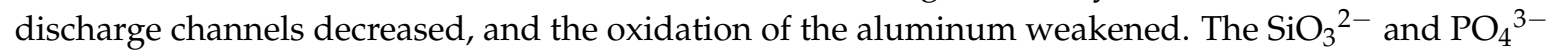
in electrolyte began to participate in the reaction massively and the formed particles deposited on the surface of the initial formed dense layer. Therefore, the content of Si and P in this layer was higher than that of the initial dense layer [30,31].

Obviously, the breakdown of dielectric was the key to the growth mechanism of the overall ceramic coating in both the arcing and the breakdown of ceramic coating. Figure 11 shows a diagram of dielectric breakdown process. At 0-50 V low voltage stage (Figure 11a), aluminum substrate reacted with the alkaline electrolyte, a layer of colloidal $\mathrm{Al}(\mathrm{OH})_{3}$ formed on the surface of aluminum substrate, which caused the most primitive colloidal dielectric breakdown behavior. The aluminum substrate started to be oxidized as a result and a layer of amorphous $\mathrm{Al}_{2} \mathrm{O}_{3}$ with certain amount of resistance formed gradually. At 100-200 V voltage stage (Figure 11b), the $\mathrm{Al}_{2} \mathrm{O}_{3}$ film thickened gradually and the pore structure formed around the discharge channels. Accordingly, the electrical breakdown and the electrolysis of water occurred at the bottom of the holes. When the voltage rose to about $300 \mathrm{~V}$ (Figure 11c), the electrolysis of water was extremely intense so that the entire pore was occupied by the produced oxygen $\left(\mathrm{O}_{2}\right)$. Oxygen bubble was ionized at a voltage drop of about $300 \mathrm{~V}$, and free electrons were generated which triggered the "electronic avalanches" (free electron impact ionization, the number of free electrons was doubled by collisions to $2^{n}$, where " $n$ " is the number of collisions) [32]. Meanwhile, the corona discharge occurred when the oxygen plasma and reactive ions began to form. As a result, the oxide coating on the bottom of the holes broke down and the plasma oxidation entered the spark discharge stage with the ceramic coating thickening rapidly.

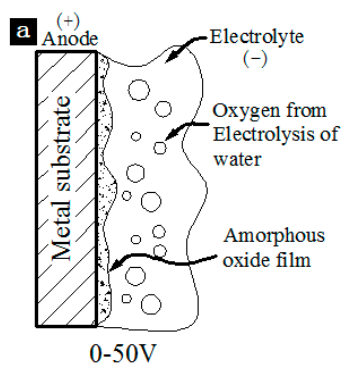

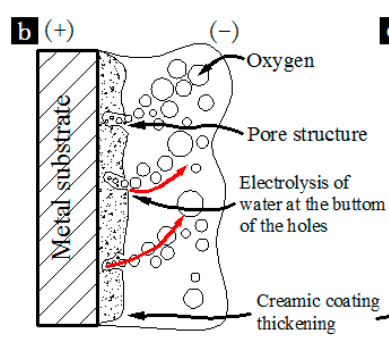

100-200V

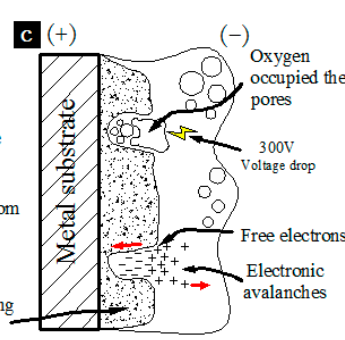

About $300 \mathrm{~V}$

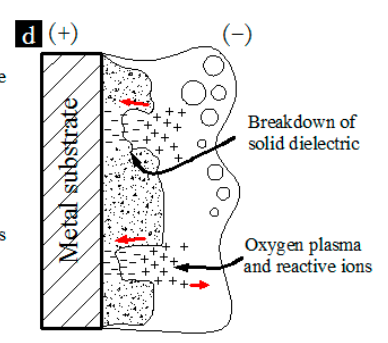

$300-400 \mathrm{~V}$

Figure 11. The diagram of dielectric breakdown at the voltage of (a) $0-50 \mathrm{~V}$; (b) 50-100 V; (c) about $300 \mathrm{~V}$; (d) 300-400 V.

However, it was different for the overall plasma oxidation of the 6061-7075 dissimilar aluminum welded part. Since a chemical/electrochemical activity difference exists between the different areas of dissimilar metal welded part, there is a reaction priority or sequence in the plasma oxidation process. Thus, the breakdown voltage of the solid-state dielectric formed on each area of the welded part was different. To verify the reaction sequence, two breakdown tests were carried out. The first test (a) sampled from an overall plasma oxidation treated welded part with a treating time of $60 \mathrm{~s}$. The second test (b) sampled from untreated welded part. The untreated 6061, 7075 and welding area samples were then plasma oxidation treated for $60 \mathrm{~s}$ under the same experimental conditions. The breakdown tests results are shown in Figure 12. 

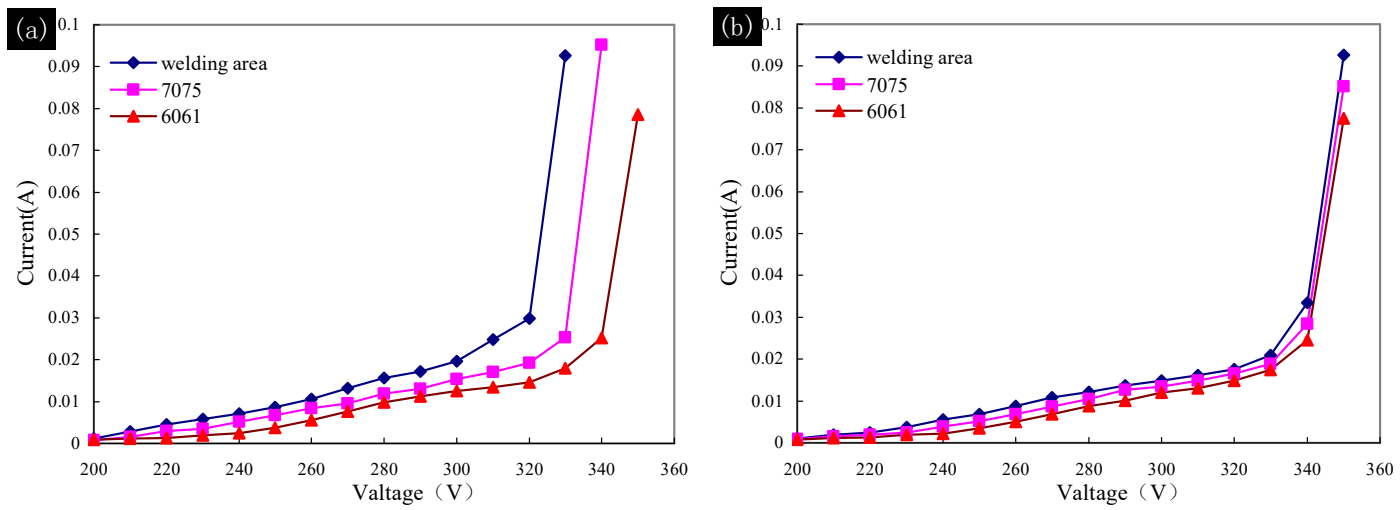

Figure 12. The breakdown tests of the samples from each area of the welded part: (a) samples from treated welded part; and (b) samples from untreated welded part and then plasma oxidation treated, respectively.

The results in Figure 12 show an interesting law. The 6061, 7075 and welding area samples in test (b) were taken from an untreated welded part, and a coating with similar thickness would grow on surface of the samples after $60 \mathrm{~s}$ plasma oxidation. The tests results in Figure $12 \mathrm{~b}$ thusly show a similar breakdown voltage of dielectric at about $340 \mathrm{~V}$. However, the breakdown voltage of samples in test (a) was different from each other, and the samples were taken from different area of overall treated welded part. The breakdown voltage of the 6061,7075 and welding area samples in test (a) was about 340, 330 and $320 \mathrm{~V}$, respectively. This was because the thickness of the ceramic coating on each area of overall treated welded part was different. The coating on welding area was the thinnest, as shown in Figure 9, so it was the easiest area to breakdown. The difference reflected the existence of reaction priority and sequence. It could be summarized as the ceramic coating formed preferentially on the surface of 6061 aluminum, followed by 7075 aluminum and then the welding area, although the ceramic coating on each area grew at the same time.

The growth mechanism of the overall ceramic coating and the phenomenon observed could be well explained based on the dielectric breakdown theory. The reaction priority and sequence were related to the physical and chemical properties of the 6061, 7075 and the welding area. The conductive performance of 6061 was better than that of 7075 and much better than welding area, because the reinforcing phase would reduce the conductivity [33]. Therefore, the current passed through the 6061 preferentially during the overall plasma oxidation of the $6061-7075$ welded part. The alkaline dielectric on the surface of 6061 broke down first along with the coating growing on the surface of 6061 , and solid-state dielectric further accelerated the formation of the coating on 6061. Then, the high impedance ceramic coating changed the surface conductivity of 6061, and the dielectric on surface of 7075 was easier to breakdown than that of 6061 in this stage. The same mechanism occurred in the welding area which caused the reaction priority and sequence observed.

\subsection{Corrosion Resistance of Ceramic Coating in Different Areas of the Welded Part}

Corrosion potential difference exists among different kinds of metals, and the conductive contact of dissimilar metals will cause serious galvanic corrosion [34]. As a result, the corrosion rate of the metal with lower corrosion potential (act as anode) increased and the metal with higher corrosion potential (act as cathode) was the opposite [35]. Accordingly, it would significantly reduce the service life of the dissimilar metal welded/connected parts. The overall micro arc oxidation could improve the corrosion resistance of each material as well as reduce the corrosion potential difference between different metals i $[15,36]$. Furthermore, the insulated integral ceramic coating isolated the 6061-7075 welded parts from corrosion media and broke the electronic circuit of corrosion, which meant the generation and extension of the corrosion were curbed effectively and it was the key technology to reduce the galvanic corrosion for lightweight alloys [15]. 
The corrosion resistance of 6061 aluminum alloy was higher than that of 7075, since the main alloying elements of the 7075 were $\mathrm{Zn}$ and $\mathrm{Mg}$ (Table 2). The main intermetallic compounds of 7075 were $\mathrm{MgZn}_{2}$ and $\mathrm{Mg}_{2} \mathrm{Si}$ [37]. However, $\mathrm{MgZn}_{2}$ and $\mathrm{Mg}_{2} \mathrm{Si}$ would dissolve and precipitate to $\mathrm{Mg}$ and $\mathrm{Zn}$ containing precipitation phases when corrosion occurred [38], which made 7075 exhibit poor corrosion resistance. On the contrary, the main intermetallic compounds of 6061 were $\mathrm{Mg}_{2} \mathrm{Si}$, which is more stable than $\mathrm{MgZn}_{2}$, resulting in better corrosion resistance [39-41]. The corrosion potential $\left(E_{\text {corr }}\right)$ and corrosion current density $\left(I_{\text {corr }}\right)$ of 6061 and 7075 are shown in Table 3. The $E_{\text {corr }}$ of 6061 and 7075 was -0.7655 and $-0.7999 \mathrm{~V}$, respectively, which verified the analysis above.

Table 3. The $E_{\text {corr }}$ and $I_{\text {corr }}$ of the uncoated/coated 6061,7075 and welding area.

\begin{tabular}{ccccccc}
\hline \multirow{2}{*}{ Areatment } & \multicolumn{2}{c}{$\mathbf{6 0 6 1}$} & \multicolumn{2}{c}{ Welding Area } & \multicolumn{2}{c}{$\mathbf{7 0 7 5}$} \\
\cline { 2 - 7 } & $E_{\text {corr }} / \mathbf{V}$ & $I_{\text {corr }} / \mathbf{e}^{-\mathbf{5}} \mathbf{A} / \mathbf{c m}^{2}$ & $E_{\text {corr }} / \mathbf{V}$ & $\boldsymbol{I}_{\text {corr }} / \mathbf{e}^{-\mathbf{5}} \mathbf{A} / \mathbf{c m}^{\mathbf{2}}$ & $\boldsymbol{E}_{\text {corr }} / \mathbf{V}$ & $I_{\text {corr }} / \mathbf{e}^{-5} \mathbf{A} / \mathbf{c m}^{\mathbf{2}}$ \\
\hline Uncoated & -0.7655 & 4.359 & -0.8633 & 6.239 & -0.7999 & 5.183 \\
Coated & -0.7172 & 2.138 & -0.7537 & 2.032 & -0.7289 & 1.636 \\
\hline
\end{tabular}

Electrochemical polarization curves of the coated/uncoated base metals (6061/7075) and welding area of the 6061-7075 dissimilar aluminum alloys friction stir welded parts are shown in Figure 13. The $E_{c o r r}$ and $I_{\text {corr }}$ were extracted from the potentiodynamic polarization curves via Tafel region extrapolation and the parameters summarized in Table 3. It was clear that the corrosion resistance of $6061 / 7075$ aluminum substrate and welding area were enhanced with the overall plasma oxidation treatment. The $E_{\text {corr }}$ of 6061 was improved from -0.7665 to $-0.7172 \mathrm{~V}$ (improved $8.9 \%$ ), and the $I_{\text {corr }}$ decreased from 4.359 to $2.138 \mathrm{e}^{-5} \mathrm{~A} / \mathrm{cm}^{2}$ (decreased 50.9\%). The $E_{\text {corr }}$ of 7075 was improved from -0.7999 to $-0.7289 \mathrm{~V}$ (improved $8.8 \%$ ) and the $I_{\text {corr }}$ was decreased from 5.183 to $1.636 \mathrm{e}^{-5} \mathrm{~A} / \mathrm{cm}^{2}$ (decreased $68.4 \%$ ). Similarly, the $E_{\text {corr }}$ of the welding area was increased to -0.7537 from $-0.8633 \mathrm{~V}$ (improved 12.7\%) and the $I_{\text {corr }}$ was decreased to 1.595 from $4.898 \mathrm{e}^{-5} \mathrm{~A} / \mathrm{cm}^{2}$ (decreased 67.4\%). All the electrochemical test results showed that the corrosion resistance of each area was improved.

Besides, the overall plasma oxidation treatment reduced the potential corrosion difference between each area. The $E_{\text {corr }}$ of the welding area was lower than the $E_{\text {corr }}$ of $6061 / 7075$ aluminum, which means that the friction stir welding reduced the corrosion resistance of the welding joint. As a result, the potential galvanic corrosion would occur first on the welding joint. However, the corrosion potential difference between 6061 and 7075 was $0.0344 \mathrm{~V}$ before overall plasma oxidation treatment, and it decreased to $0.0126 \mathrm{~V}$ with the overall treatment. Moreover, the $E_{c o r r}$ difference between 6061 and welding area decreased from 0.0978 to $0.0365 \mathrm{~V}$, and the $E_{\text {corr }}$ difference of 7075 and welding area decreased from 0.0634 to $0.0239 \mathrm{~V}$. All the data indicate that corrosion potential difference between different areas was reduced which meant better galvanic corrosion resistance and overall protective performance.
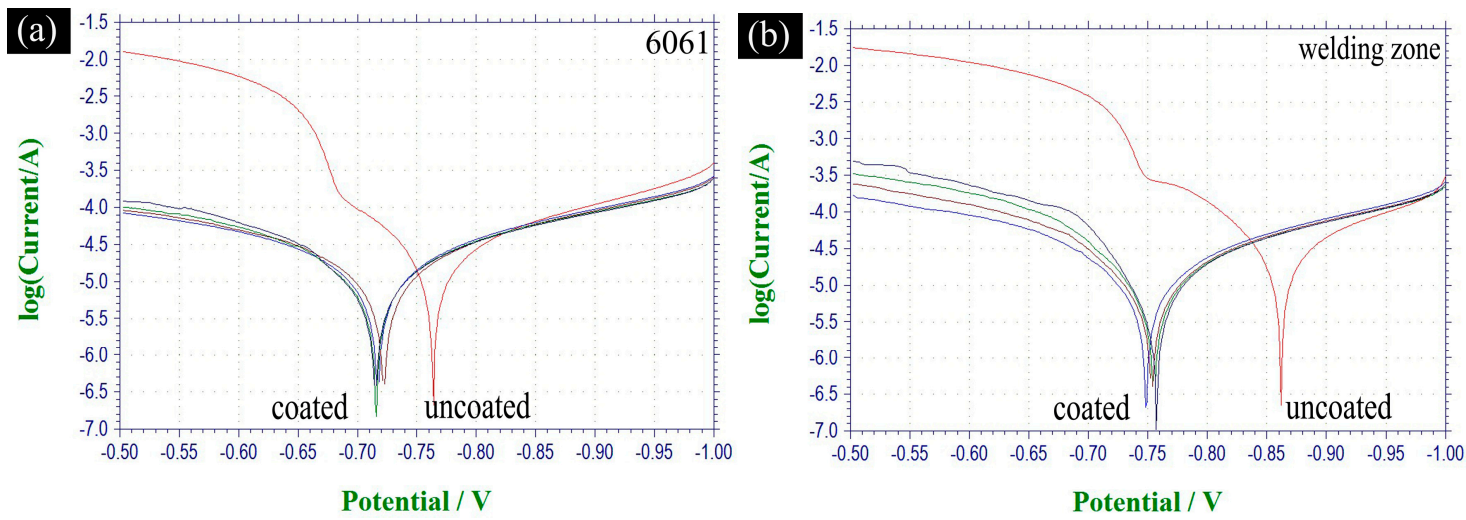

Figure 13. Cont. 


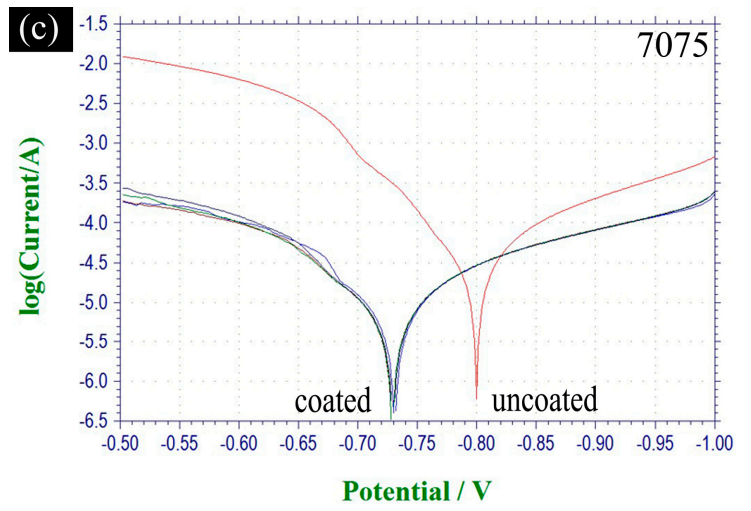

Figure 13. Polarization curves of: (a) 6061; (b) welding area; and (c) 7075.

\section{Conclusions}

(1) The 6061-7075 dissimilar aluminum welded part was successfully treated by overall plasma oxidation and the welded part was integrally wrapped by a ceramic coating.

(2) The ceramic coating on the surface of welding area was different from the coating on base metal (6061/7075) in both morphology and composition. The coating on the welding area was mainly made of $\alpha-\mathrm{Al}_{2} \mathrm{O}_{3}$ and $\gamma-\mathrm{Al}_{2} \mathrm{O}_{3}$, while the coating on the 6061 and 7075 consisted of $\alpha-\mathrm{Al}_{2} \mathrm{O}_{3}$, $\gamma-\mathrm{Al}_{2} \mathrm{O}_{3}$, mullite and small amount of P-containing amorphous.

(3) Reaction priority and sequence during overall plasma oxidation of 6061-7075 welded part was observed. The plasma oxidation reaction prefers to occur in the sequence of 6061 aluminum, 7075 aluminum, and welding area.

(4) The overall plasma oxidation improved the corrosion resistance of all areas on 6061-7075 welded part and reduced the corrosion potential difference between different areas.

Acknowledgments: This paper was supported by National key research and development program of China (2016YFB0301105 and 2017YFB0103904), and the Key research and development plan of Shandong province (2017CXGC0404).

Author Contributions: Yanfei Chen conceived and designed the experiments, and wrote the paper after a comprehensive analysis of the data; Xiaocun Song performed SEM and EDS analysis of the ceramic coating; Jixue Zhou performed the dielectric breakdown tests and analyzed the results; Hongtao Liu analyzed the data of electrochemical experiments; Yuansheng Yang contributed the XRD equipment and provided some technical guidance.

Conflicts of Interest: The authors declared that they have no conflicts of interest to this work.

\section{References}

1. Shen, H.-S. Functionally Graded Materials: Nonlinear Analysis of Plates and Shells; CRC Press: Boca Raton, FL, USA, 2016.

2. Levashov, E.A.; Gotman, I. Functionally graded materials. In Concise Encyclopedia of Self-Propagating High-Temperature Synthesis; Elsevier: Amsterdam, The Netherlands, 2017; pp. 135-137.

3. Xiao, K.; Dong, C.; Wei, D.; Wu, J.; Li, X. Galvanic corrosion of magnesium alloy and aluminum alloy by kelvin probe. J. Wuhan Univ. Technol. Mater. Sci. Ed. 2016, 31, 204-210. [CrossRef]

4. Guo, H. The Electrochemical Corrosion Behavior and Mechanism of Micro-Arc Oxidation Coatings on Magnesium Alloys; Lanzhou University of Technology: Lanzhou, China, 2014.

5. Wang, S.; Liu, P. The technology of preparing green coating by conducting micro-arc oxidation on az91d magnesium alloy. Polish J. Chem. Technol. 2016, 18, 36-40. [CrossRef]

6. Tran, Q.-P.; Kuo, Y.-C.; Sun, J.-K.; He, J.-L.; Chin, T.-S. High quality oxide-layers on Al-alloy by micro-arc oxidation using hybrid voltages. Surf. Coat. Technol. 2016, 303, 61-67. [CrossRef] 
7. Yang, S.; Zhou, L.; Cheng, X. Micro-arc oxide film of aluminum coating pre-sprayed on AZ31 magnesium alloy. In Magnesium Technology; Springer: Berlin, Germany, 2016; pp. 291-295.

8. Guo, S.; Leavitt, J.J.; Zhou, X.; Xie, Y.; Tietze, S.; Zhu, Y.; Lawver, A.; Lahti, E.; Zhang, J. Effects of flow, si inhibition, and concurrent corrosion of dissimilar metals on the corrosion of aluminium in the environment following a loss-of-coolant accident. Corros. Sci. 2017, 128, 100-109. [CrossRef]

9. Guo, W.; You, G.; Yuan, G.; Zhang, X. Microstructure and mechanical properties of dissimilar inertia friction welding of 7A04 aluminum alloy to AZ31 magnesium alloy. J. Alloy. Compd. 2017, 695, 3267-3277. [CrossRef]

10. Morita, M.; Naito, Y.; Niki, E.; Yoshikawa, T. Antioxidant action of fermented grain food supplement: Scavenging of peroxyl radicals and inhibition of plasma lipid oxidation induced by multiple oxidants. Food Chem. 2017, 237, 574-580. [CrossRef] [PubMed]

11. Chen, P.-Y.; Wu, C.-C.; Fan, Y.-T.; Lin, S.-D. Nano-scale oxide layer prepared by plasma oxidation on single-crystalline aluminum film, Nanotechnology (IEEE-NANO). In Proceedings of the IEEE 16th International Conference on Nanotechnology (IEEE-NANO), Sendai, Japan, 22-25 August 2016; pp. 809-811.

12. Xiang, N.; Song, R.-G.; Zhuang, J.-J.; Song, R.-X.; Lu, X.-Y.; Su, X.-P. Effects of current density on microstructure and properties of plasma electrolytic oxidation ceramic coatings formed on 6063 aluminum alloy. Trans. Nonferrous Met. Soc. China 2016, 26, 806-813. [CrossRef]

13. Zhen, C.; Li, C.; Yi, J.; Lu, S.; Gao, Y.; Zhang, K. Corrosion behavior of high strength aluminium alloys 6061 and 7075 in simulating marine atmosphere. Mater. Prot. 2014, 47, 38-41.

14. Cui, L.-Y.; Gao, S.-D.; Li, P.-P.; Zeng, R.-C.; Zhang, F.; Li, S.-Q.; Han, E.-H. Corrosion resistance of a self-healing micro-arc oxidation/polymethyltrimethoxysilane composite coating on magnesium alloy AZ31. Corros. Sci. 2017, 118, 84-95. [CrossRef]

15. Chen, Y.; Zhou, J.; Liu, H.; Song, X.; Yang, Y. Overall micro-arc oxidation treatment for AZ31B-6061 magnesium-Aluminium dissimilar metal connecting parts. Corros. Eng. Sci. Technol. 2017, 52, 470-475. [CrossRef]

16. Ning, H.; Reece, M.J.; Smeacetto, F.; Salvo, M. Oxidation protective glass-ceramic coating for higher manganese silicide thermoelectrics. J. Mater. Sci. 2016, 51, 9484-9489. [CrossRef]

17. Yang, Y.; Zhou, L. Improving corrosion resistance of friction stir welding joint of 7075 aluminum alloy by micro-arc oxidation. J. Mater. Sci. Technol. 2014, 30, 1251-1254. [CrossRef]

18. Tang, H.; Yu, D.; Luo, Y.; Wang, F. Preparation and characterization of ha microflowers coating on AZ31 magnesium alloy by micro-arc oxidation and a solution treatment. Appl. Surf. Sci. 2013, 264, 816-822. [CrossRef]

19. Arrabal, R.; Matykina, E.; Skeldon, P.; Thompson, G. Coating formation by plasma electrolytic oxidation on ZC71/SiC/12p-t6 magnesium metal matrix composite. Appl. Surf. Sci. 2009, 255, 5071-5078. [CrossRef]

20. Montemor, M. Corrosion issues in joining lightweight materials: A review of the latest achievements. Phys. Sci. Rev. 2016, 1. [CrossRef]

21. Stojadinović, S.; Vasilić, R.; Radić, N.; Tadić, N.; Stefanov, P.; Grbić, B. The formation of tungsten doped al $2 \mathrm{o} 3$ /zno coatings on aluminum by plasma electrolytic oxidation and their application in photocatalysis. Appl. Surf. Sci. 2016, 377, 37-43. [CrossRef]

22. Mi, T.; Jiang, B.; Liu, Z.; Fan, L. Plasma formation mechanism of microarc oxidation. Electrochim. Acta 2014, 123, 369-377. [CrossRef]

23. Byon, E.; Jeong, Y.; Takeuchi, A.; Kamitakahara, M.; Ohtsuki, C. Apatite-forming ability of micro-arc plasma oxidized layer of titanium in simulated body fluids. Surf. Coat. Technol. 2007, 201, 5651-5654. [CrossRef]

24. Yeh, S.-C.; Tsai, D.-S.; Wang, J.-M.; Chou, C.-C. Coloration of the aluminum alloy surface with dye emulsions while growing a plasma electrolytic oxide layer. Surf. Coat. Technol. 2016, 287, 61-66. [CrossRef]

25. Wang, P.; He, Y.-D.; Deng, S.-J.; Zhang, J. Porous $\alpha$-Al2o3 thermal barrier coatings with dispersed pt particles prepared by cathode plasma electrolytic deposition. Int. J. Min. Metall. Mater. 2016, 23, 92-101. [CrossRef]

26. Wang, Y.; Shao, Y. Microstructure, corrosion and wear resistances of microarc oxidation coating on $\mathrm{Al}$ alloy 7075. Acta Metall. Sin. 2011, 47, 455-461.

27. Xue, X. Effect of $\mathrm{SiCp}$ reinforcement on growth of microarc oxidation film on aluminium matrix compsite. Acta Metall. Sin. 2006, 4, 350-354.

28. She, J.; Ohji, T. Fabrication and characterization of highly porous mullite ceramics. Mater. Chem. Phys. 2003, 80, 610-614. [CrossRef] 
29. Lu, C.; Wand, Q.; Liang, J.; Li, Q.; Peng, Z.; Liu, B. Forming process of black micro-arc oxidation coatings on aluminium alloys. Chin. J. Nonferrous Met. 2015, 25, 3430-3438.

30. Tinoco, J.; Estrada, M.; Romero, G. Room temperature plasma oxidation mechanism to obtain ultrathin silicon oxide and titanium oxide layers. Microelectron. Reliab. 2003, 43, 895-903. [CrossRef]

31. Wang, Z.; Jiang, S.; Zhu, Y.; Zhou, J.; Zhou, J.; Li, Z.; Cen, K. Investigation on elemental mercury oxidation mechanism by non-thermal plasma treatment. Fuel Process. Technol. 2010, 91, 1395-1400. [CrossRef]

32. Venugopal, A.; Srinath, J.; Krishna, L.R.; Narayanan, P.R.; Sharma, S.; Venkitakrishnan, P. Corrosion and nanomechanical behaviors of plasma electrolytic oxidation coated aa7020-t6 aluminum alloy. Mater. Sci. Eng. A 2016, 660, 39-46. [CrossRef]

33. Gao, Y.; Morisada, Y.; Fujii, H.; Liao, J. Dissimilar friction stir lap welding of magnesium to aluminum using plasma electrolytic oxidation interlayer. Mater. Sci. Eng. A 2017, 711, 109-118. [CrossRef]

34. Katkar, V.A.; Gunasekaran, G. Galvanic corrosion of AA6061 with other ship building materials in seawater. Corrosion 2015, 72, 400-412. [CrossRef]

35. Palani, S.; Hack, T.; Deconinck, J.; Lohner, H. Validation of predictive model for galvanic corrosion under thin electrolyte layers: An application to aluminium 2024-cfrp material combination. Corros. Sci. 2014, 78, 89-100. [CrossRef]

36. Duarte, L.T.; Bolfarini, C.; Biaggio, S.R.; Rocha-Filho, R.C.; Nascente, P.A. Growth of aluminum-free porous oxide layers on titanium and its alloys Ti-6Al-4V and Ti-6Al-7Nb by micro-arc oxidation. Mater. Sci. Eng. C 2014, 41, 343-348. [CrossRef] [PubMed]

37. Venugopal, A.; Ramesh Narayanan, P.; Sharma, S.; George, K.M. Effect of micro arc oxidation treatment on the corrosion and stress corrosion cracking (scc) behaviours of AA7020-T6 aluminum alloy in 3.5\% $\mathrm{NaCl}$ solution. In Materials Science Forum; Trans Tech Publication: Basel, Switzerland, 2015; pp. 639-642.

38. Shen, D.; Li, G.; Guo, C.; Zou, J.; Cai, J.; He, D.; Ma, H.; Liu, F. Microstructure and corrosion behavior of micro-arc oxidation coating on 6061 aluminum alloy pre-treated by high-temperature oxidation. Appl. Surf. Sci. 2013, 287, 451-456. [CrossRef]

39. Krishna, L.R.; Poshal, G.; Jyothirmayi, A.; Sundararajan, G. Relative hardness and corrosion behavior of micro arc oxidation coatings deposited on binary and ternary magnesium alloys. Mater. Des. 2015, 77, 6-14. [CrossRef]

40. Liu, C.; Liu, P.; Huang, Z.; Yan, Q.; Guo, R.; Li, D.; Jiang, G.; Shen, D. The correlation between the coating structure and the corrosion behavior of the plasma electrolytic oxidation coating on aluminum. Surf. Coat. Technol. 2016, 286, 223-230. [CrossRef]

41. Huang, I.; Evan, W. Uniform Corrosion and General Dissolution of Aluminum Alloys 2024-T3, 6061-T6, and 7075-T6. Ph.D. Thesis, the Ohio State University, Columbus, OH, USA, 2016. 